\title{
Encouraging male involvement in sexual and reproductive health: family planning service providers' perspectives
}

\author{
Razaq Akintunde Akindele ${ }^{1}$, Wasiu Olalekan Adebimpe ${ }^{2, *}$ \\ ${ }^{1}$ Department of Obstetrics and Gynaecology, LAUTECH Teaching Hospital PMB 5000 Osogbo, Nigeria \\ ${ }^{2}$ Department of Community Medicine, Osun State University, Osogbo, Nigeria
}

Received: 21 January 2013

Accepted: 13 February 2013

\section{*Correspondence:}

Dr. Wasiu Olalekan Adebimpe,

E-mail: lekanadebimpe@gmail.com

(c) 2013 Akindele RA et al. This is an open-access article distributed under the terms of the Creative Commons Attribution License, which permits unrestricted use, distribution, and reproduction in any medium, provided the original work is properly cited.

\begin{abstract}
Introduction: Despite the advantaged position of men in sexual, family and reproductive health matters, their roles in family planning (FP) remains largely invisible. This study examined perception of family planning care providers towards improving male involvement in family planning services utilization in Southwestern Nigeria.

Methods: Descriptive cross sectional qualitative study of perception of secondary care level family planning service providers from four out of the six states in Southwestern Nigeria selected by simple random sampling. A total of eight focus group discussions of 8 eligible providers each were held using a pre tested focus group discussion guide. Discussions were carried out during the monthly providers meetings.

Results: All discussants were trained FP service providers. All respondents reported that men have not been coming frequently to the FP clinic either as a client or to accompany their wives to the clinic. About two-third of discussants said that the most important barriers to male involvement include a lack of accurate information on contraception.

Suggested community based strategies to improve male involvement include creation of awareness on the media, during festivals, sports events, workplaces and during agric cooperatives in the rural areas, using men as outreach workers to reach and educate other men. Clinic based strategies suggested include establishment of stand-alone clinics for men, creating separate hours/entrances for men, giving prompt attention to men, use of men as counselors arranging clinic sessions at convenient time like evenings or weekends and encouraging male friendly services during FP clinic counseling sessions.
\end{abstract}

Conclusion: If the acceptance of family planning and contraceptive prevalence rate must improve, men should also be targeted by family planning programme/care providers.

Keywords: Family planning, Male involvement, Barriers

\section{INTRODUCTION}

Most fertility figures and findings in the recent past have been dominated by findings almost exclusively to women. Men were either neglected or not carried along, and regarded as irrelevant in reproductive health issues. Most viewed women as the target group and paid little attention to the role that men might have despite being the significant factor in decision making in the family. ${ }^{2}$ Regrettably, policies and programs based on such findings have not had expected success in increasing contraceptive prevalence and simultaneously reducing overall fertility in sub-Saharan Africa.

After the 1994 International Conference on Population and Development (ICPD) in Cairo, the world has seen a shift in paradigm away from focused family planning programs towards reproductive and sexual health more generally. ${ }^{1}$ Whilst men are deemed to have 'responsibilities', women are said to have 'rights' with regard to making choices about reproductive health, women's fertility preferences and behaviour are strongly 
influenced by reproductive motivation of women by their husbands. ${ }^{3}$

Also in most developing countries, women carry the burden of responsibility on contraceptive use often with little or no support and sometimes with great resistance from their male partners; while on many occasions, men facilitated contraceptive use for their partners. ${ }^{4}$ Studies have shown that in many developing countries, a significant proportion of women still use contraceptives without the knowledge of their husbands.. Subsequently, many women are afraid to raise the issue of contraception for fear that their partners might respond violently. Traditional notions about gender roles and family, together with economic concerns, shaped fertility decision making with the man at the center. Family planning program planners tend to assume that men are opposed to family planning and will, if involved in reproductive decision making, prevent women from regulating their fertility. Available data however suggest that the most successful family planning programs target men as well as women and promote communication about contraception between spouses. ${ }^{5}$

Despite general beliefs that men are well aware of family planning, myths and misconceptions for example that vasectomy is synonymous with castration, characterize and dilute their knowledge, and this would ultimately affect their support for family planning services for them and their wives. The shift in focus on men's reproductive health was influenced by the 1994 Cairo ICPD Action Plan to promote gender equality and equity, empower women, and improve family health in society. Changing and improving the way in which men are involved in reproductive health can only have a positive impact on women's, men's, and children's health. Educating and counseling men about contraceptive choices is therefore essential if they are to be supportive of women's reproductive health. ${ }^{6}$

Ignoring men in fertility research and programmes undermines the need for successful reproductive health indices which is central to the achievement of the Millennium Development Goals (MDGs). It is thus important to put Health Care Workers (HCWs) in the picture when planning effective population control activities towards addressing the family life and sexual behaviour of men. The objective of this study is to examined perception of family planning care providers towards improving male involvement in family planning services utilization in Southwestern Nigeria.

\section{METHODS}

This was a descriptive cross sectional study of perception of family planning care providers towards encouraging male involvement in family planning services in Southwestern Nigeria. The Southwestern region comprising about one fifth of Nigerian population, have six states with an average contraceptive prevalence rate of about $13.2 \%$ which is representative of the national figures. $^{7}$ In each of the states are health care workers providing family planning services at primary, secondary and tertiary health care levels. Family planning care providers at the secondary level of care or general hospitals were recruited for this study, and the person must be working in FP clinics as at present, and have been providing service for at least a year.

Four out of the six states were selected by simple random sampling employing simple balloting, and this included Oyo, Osun, Ondo and Lagos states. In each state, two focus group discussions of eight eligible FP providers each was carried out. The discussions were carried out during the monthly FP clinic providers meetings which are usually hosted by the state ministry of health. A total of eight focus group discussions were held using a focus group discussion guide. Discussions were made in both English and vernacular to ensure good understanding of questions. The use of an experienced qualitative research moderator was employed during the discussion to further guide the conduct of this focus group discussion.

Variables examined in the research instruments include frequency of men coming to FP clinics, why they may not have been coming, and strategies to improve their access to FP clinics and their perceived role at improving men's patronage of FP services. Ethical clearance to conduct the study was obtained from the ethical review committee of LAUTECH Teaching Hospital Osogbo, and permissions received from the Ministry of Health and individual discussants.

Qualitative responses were analyzed using simple content analysis (i.e. in terms of nature and responses to questions as well as cogency and frequency of points raised in the various questions). One possible limitation of this study is that the findings may not be generalized on FP providers at primary or tertiary level of care. An excel sheet was used to enter socio-demographic data of the discussants and resulting analyzed data was presented in form of a simple frequency table.

\section{RESULTS}

All focus group discussants were family planning service providers who had been working in the unit for a minimum of two years, and had special training or postnursing experience in family planning. They all said that their clinics were established to attend to all clients irrespective of gender. About one third of them runs integrated Family Planning/Sexual and Reproductive Health (FP/SRH) services clinic sponsored or supported by Non Governmental Organizations (NGOs) and donor agencies. All respondents reported that men have not been frequent in coming to the FP clinic either as a client on their own or to accompany their wives to the clinic.

About two-third of discussants suggested that the most important barrier to male involvement include a lack of 
accurate information on contraception for men. Other reasons given by majority of the other respondents include health provider's bias against male gender in dealings and counseling, that methods available for men are limited and access is not readily available. Suggested community based strategies to improve male involvement in FP include the creation of awareness on the media, creating awareness during festivals, sports events, workplaces and during agric cooperatives in the rural areas. Clinic based strategies suggested include establishment of stand-alone clinics for men, creating separate hours/entrances for men, provision of integrated Reproductive Health $(\mathrm{RH})$ services and use of fellow men as counselors.

Table 1: Socio-demographic characteristics of focus group discussants.

\begin{tabular}{|c|c|c|}
\hline Variables $(n=64)$ & Frequency & Percentage \\
\hline \multicolumn{3}{|l|}{ Age in years } \\
\hline $21-30$ & 3 & 4.7 \\
\hline $31-40$ & 32 & 50 \\
\hline $41-50$ & 26 & 40.6 \\
\hline $51-60$ & 3 & 4.7 \\
\hline \multicolumn{3}{|l|}{ Sex } \\
\hline Female & 63 & 98.4 \\
\hline Male & 1 & 1.6 \\
\hline \multicolumn{3}{|l|}{ Religion } \\
\hline Christianity & 35 & 54.7 \\
\hline Islam & 28 & 43.7 \\
\hline Traditional & 1 & 1.6 \\
\hline Others & 0 & 0 \\
\hline \multicolumn{3}{|c|}{ Highest level of education } \\
\hline Primary/Secondary & 0 & 0 \\
\hline Diploma in Nursing & 2 & 3.2 \\
\hline $\begin{array}{l}\text { Post basic } \\
\text { nursing(FP) }\end{array}$ & 55 & 85.8 \\
\hline Degree & 6 & 9.4 \\
\hline Post graduate & 1 & 1.6 \\
\hline Others & 0 & 0 \\
\hline \multicolumn{3}{|l|}{ Marital status } \\
\hline Married & 52 & 81.2 \\
\hline Single & 4 & 6.3 \\
\hline Separated & 5 & 7.8 \\
\hline Widowed/divorced & 3 & 4.7 \\
\hline Others & 0 & 0 \\
\hline \multicolumn{3}{|c|}{ No. of years worked in FP clinic } \\
\hline $2-5$ years & 28 & 43.7 \\
\hline $6-10$ years & 26 & 40.6 \\
\hline $11-15$ years & 9 & 14.1 \\
\hline$>15$ years & 1 & 1.6 \\
\hline
\end{tabular}

All respondents believed that reasons for involving men in family planning programmes include that men play dominant role in decision-making in the family. Other reasons stated by majority of discussants are that men are family heads and exerts a lot of influences on women's decision, that the support of men matters most especially financially, that men wants contraception most especially male methods but they lack access to adequate information on contraception, that most men approve their wives of family planning, that men may oppose their wives in their bid to adopt family planning if not carried along, and that men could serve as advocates to abrogate religious and cultural barriers against men's sexuality, contraception and promotion of gender equity.

All discussants said they could not see anything special in their clinic set up that could discourage men from coming, and have also not seen any special thing that could attract them to the clinic. As HCWs, all respondents were all convinced that the role of men in family planning is important and central to sexual and reproductive health $(\mathrm{SRH})$, and could increase couple year protection rates of contraceptives. All discussants felt they could personally encourage men into accepting FP methods.

Some of the ways described by majority of discussants include welcoming men warmly at the FP clinic, disper myths and misconceptions about FP and SRH, lay emphasis on how men could be supportive to their wives such as reminding pill takers, not wasting the time of men unnecessarily in the clinic, use visual aids showing male examples, tailor RH issues towards their concern like prostate enlargement and sexually transmitted infections, using men as outreach to reach and educate other men, encouraging men to also use FP, arranging clinic sessions at convenient time like evenings or weekends and encouraging male friendly services during counseling sessions.

\section{DISCUSSIONS}

Respondents believed that men are decision makers and may influence family decisions to adopt contraception. This supports other studies in which men as head of families were described as sole decision makers in their family affairs, and these decisions could affect adoption and practice of contraception by their wives. ${ }^{8,9}$ Men have a domineering position as heads of family and being the bread winner in most cases. They also gain socially and economically from having large numbers of children, and this reproductive preferences and motivation influence their wives reproductive outcome. In patrichial society where men largely make household decisions, the need to include men in all matters that required joint spousal decision is critical in achieving key reproductive health goals.

This fact that respondents recognized the fact that men can oppose their wife's FP bid if not carried along supports another study, ${ }^{10}$ in which men's negative attitude was found to be a major reason why their wives fail to practice family planning, even when the latter are motivated to do so. In this study, men was said could serve as advocates to abrogate religious and cultural barriers against men's sexuality and contraception, on 
which a man could capitalize when opposing his wife's bid to adopt contraception.. This supports other studies., 4 In many developing countries, a significant proportion of women use contraceptives without the knowledge of their husbands. In some cultures within the sub-Saharan African countries, men actually oppose their wife's adoption of contraceptives. Men's opposition to contraception is hinged on many reasons including that it encourages irresponsible sexual behaviour.

This study found out that a lack of accurate information on contraception for men could be a possible barrier to male involvement. This may however disagree with a study in which most men had high awareness of family planning, and that decision about family planning should be made jointly by the spouses instead of being the prerogative of either. ${ }^{11}$ Studies have also shown that majority of men want or approves contraception, and also recognized the need for FP methods, more so they like having higher number of children but which economically they may not cater for. ${ }^{12}$

Men in this environment still hold the idea that women are morally weak and unable to control their appetite, body and sexuality. There is the belief that "no matter who and how a woman is, her intellect is very small" and as such, her use of family planning should be subjected to the husband's control. It is thus important that the 1994 International Conference on Population and Development (ICPD) in Cairo program of actions be reviewed to bring out more actions to solidify the statement on male responsibilities and participation. ${ }^{13}$

Men like being recognized, and this may inform the need to warmly welcome them whenever they come around to FP clinics. Because they are usually busy in business, work and farm among others, it may be important not to waste the time of men whenever they come to the clinic. They should be attended to with immediate effect. This would also encourage other women to bring their husbands to the next clinic when they find out that women who brings their husbands to the clinic are being attended to promptly in an attempt not to waste the time of their husbands. This may also inform the need to schedule men's clinic to evenings and weekends when they will be less busy and when they can be duely counseled without being in a hurry. In addition, health care workers may need to step up counseling to men and dispel rum ours and myths about contraception. For example, castration was believed by men to be synonymous to vasectomy, and this has made many men not to have interest in FP. Rather attention should be drawn to positive uses of FP methods such as prevention of Sexually Transmitted Infections (STIs) using FP methods for dual protection.

\section{CONCLUSION}

FP providers believed that men have roles to play in SRH including family planning. They beloved that they could improve awareness of FP among men, provide more men friendly contraceptive care and services to encourage men to come to FP clinics through a combination of both clinic and community based interventions that would eventually increase contraceptive utilization and use prevalence rate.

\section{ACKNOWLEDGEMENTS}

We thank the Family Planning coordinators in the states in which this research work was conducted, and the family planning providers for making the data collection process a success.

\section{Funding: No funding sources \\ Competing interests: None declared \\ Ethical approval: Not required}

\section{REFERENCES}

1. Collumbien M, Hawkes S. Missing men's messages: does the reproductive health approach respond to men's sexual health needs? Cult Health Sex 2000;2:135-50.

2. RHM 2009. Men and Reproductive Health Overview. RHM archives. Available at http://www.rho.org/ html/menrh-links.html. Accessed $21^{\text {st }}$ August 2012.

3. Pachauri S. Male involvement in reproductive health care. J Indian Med Assoc 2001;99:138-41.

4. Shattuck D, Kerner B, Gilles K, Hartmann M, Ng'ombe T, Guest G. Encouraging contraceptive uptake by motivating men to communicate about family planning: the Malawi Male Motivator project. Am J Public Health 2011;101:1089-95.

5. Karra MV, Stark NN, Wolf J. Male involvement in family planning: a case study spanning five generations of a south Indian family. Stud Fam Plann 1997;28:24-34.

6. Bustamante-Forest R, Giarratano G. Changing men's involvement in reproductive health and family planning. Nurs Clin North Am 2004;39:301-18.

7. National Population Commission (NPC) 2000. Nigeria demographic and health survey. Calverton Maryland. NPC and ORC Macro; 1999:45-47.

8. Mistik S, Naçar M, Mazicioğlu M, Cetinkaya F. Married men's opinions and involvement regarding family planning in rural areas. Contraception 2003;67:133-7.

9. Lasee A, Becker S. Husband-wife Communication about Family Planning and Contraceptive Use in Kenya. International Family Planning Perspectives 1997;23:15-20.

10. Fapounda ER, Todaro MP. Family Structure, Implicit Contracts, and the Demand for Children in Southern Nigeria. Population and Development Review 1988;14:571-94.

11. Hartmann M, Gilles K, Shattuck D, Kerner B, Guest G. Changes in couples' communication as a result of 
a male-involvement family planning intervention. J Health Commun 2012;17:802-19.

12. Ijadunola MY, Abiona TC, Ijadunola KT, Afolabi OT, Esimai OA, OlaOlorun FM. Male involvement in family planning decision making in Ile-Ife, Osun
State, Nigeria. Afr J Reprod Health 2010;14(4 Spec no.):43-50.

13. Levy J. Reaching the Goals of Cairo Male Involvement in Family Planning, 2008. Available at http://www.gi.unc.edu/research/carolina.papers/heal thpapers.htm.

DOI: $10.5455 / 2320-1770 . i j \operatorname{rog} 20130602$

Cite this article as: Akindele RA, Adebimpe WO. Encouraging male involvement in sexual and reproductive health: family planning service providers' perspectives. Int J Reprod Contracept Obstet Gynecol 2013;2:119-23. 